\title{
Overwintering strategy of sandeel ecotypes from an energy/predation trade-off perspective
}

\author{
Mikael van Deurs*, Asbjørn Christensen, Christina Frisk, Henrik Mosegaard \\ National Institute of Aquatic Resources, Technical University of Denmark, Jægersborg Alle 1, Charlottenlund Castle, \\ 2920 Charlottenlund, Denmark
}

\begin{abstract}
The overwintering strategy is widespread among planktivorous fish from temperate to sub-polar regions, and is particularly pronounced in sandeel ecotypes. This adaptation is presumably a behavioural adaptation to strong seasonal fluctuation in prey availability, day length and temperature. Yet so far, insight into the evolutionary and ecological mechanisms involved has remained elusive. In the present study, the overwintering behaviour is considered to be a strategy requiring 2 annual decisions: When to end overwintering and when to start overwintering, which combined comprise the timing and duration of the foraging window. We present a model framework for sandeel that demonstrates how the optimal timing of the foraging window involves a trade-off between energy gain and survival probability. Physiological components of the model are based on laboratory experiments with sandeel, some of which are presented as part of this study. The major findings were that optimisation of individual fitness is strictly dependent on the temporal match between the foraging window and the peak period of the spring burst of zooplankton. In contrast, fitness is only marginally reduced in individuals that fail to optimise the foraging window in relation to the level of mortality and prey availability experienced during the zooplankton spring burst. Lastly, overwintering remained the optimal strategy, even in scenarios where winter prey abundances approached abundances near that of the peak abundance in spring.
\end{abstract}

KEY WORDS: Ammodytes · Life history optimization · Fitness · Bioenergetics · Foraging window · Mismatch

\section{INTRODUCTION}

Many zooplanktivorous fish species in temperate and sub-polar regions experience strong seasonal fluctuations in prey availability, and often rely on a transient zooplankton production fuelled by the exponential primary production in late spring, which is triggered by temperature-induced stratification and increasing day length. As a life cycle adaptation to the harsh conditions, many species build energy reserves to avoid starvation (Schultz \& Conover 1997, 1999, Biro et al. 2005, Hurst 2007) and some even overwinter in a state of passiveness and stop actively searching for food. Such an overwintering strategy has been reported for a number of species of high commercial and ecological value (e.g. Winslade 1974a, Huse \& Ona 1996, Kaartvedt et al. 2009), and is particularly pro- nounced in sandeel ecotypes. The archetypical example of this ecotype is the Ammodytes genus. Species of this genus can remain buried in the sediment for up to 10 mo (Winslade 1974a). However, insight into the evolutionary and ecological mechanisms underlying the overwintering strategy in fish has so far remained largely elusive.

The consequence of high mortality due to predation is that many individuals will not live long enough to reproduce. In this case foraging decisions become a trade-off between predation mortality and energy gain maximisation, also referred to as the energy/predation trade-off (Houston \& McNamara 1999). The discovery of the energy/predation trade-off (e.g. Mittelbach 1981, Werner et al. 1983) led to a bloom of theoretical and empirical research suggesting that this trade-off impacts not only on the level of the individual but also 
at the level of populations and entire ecosystems (e.g. Werner \& Anholt 1993, Lima 1998). Sub-maximal growth, temporal and spatial variation in distribution of prey organisms and their predators, and climate change-induced compensatory foraging activity are just some of the consequences of the energy/predation trade-off (Mangel \& Stamps 2001, Biro et al. 2003, 2006, 2007, Dill et al. 2003, Schmitz et al. 2008).

In the present study, we adopt the principles of the energy/predation trade-off in order to shed light on the evolutionary and ecological processes underlying the overwintering strategy. We consider the overwintering strategy as a plastic behaviour involving 2 annual decisions: When to end overwintering and when to start overwintering. The combination of these 2 decisions comprises the timing of the foraging window during which the individual exploits the food regime of the habitat. The optimal foraging window is defined as the one that maximises fitness (lifetime reproductive index; $R_{0}$ ). In this context we ask the following questions: (1) Is overwintering also the optimal strategy even when winter prey abundance (background food level) is high enough to support a positive surplus energy budget? (2) What is the optimal timing of the foraging window, and how is it influenced by predation mortality (including fishing mortality) and food regime (for example the intensity and timing of the zooplankton spring burst)? (3) What is the fitness-related incentive of adapting to changes in mortality and food regime? In order to answer these questions, we developed a simple (few parameters) generic model framework that linked mortality, bioenergetics, physiology and behaviour of the lesser sandeel Ammodytes marinus. Parameterisation of the model was based on values from the literature and our own recently performed experiments. In these experiments, stomach evacuation rate, stomach capacity and metabolism were measured (see Supplement 1 at www.int-res.com/articles/ suppl/m416p201_supp.pdf for details). The overwintering behaviour and annual life cycle of lesser sandeels is well documented and relatively simple to model as dispersal of lesser sandeel larvae is limited (Christensen et al. 2008) and adults are highly residential (Gauld 1990, Pedersen et al. 1999, van der Kooij et al. 2008). Lesser sandeels reach sexual maturity around the age of $2 \mathrm{yr}$ and subsequently spawn in December/January (Macer 1966, Bergstad et al. 2001). They are a commercially valuable, short-lived, trophic key species (e.g. Furness 1990, Hain et al. 1995, Furness 2002, Frederiksen et al. 2005, Engelhard et al. 2008) occupying temperate and sub-polar ecosystems worldwide (e.g. Sherman et al. 1981, Brêthes et al. 1992, Van Pelt et al. 1997, Yamada 2009).

\section{MATERIALS AND METHODS}

Overview of the model. We developed an individualbased bioenergetics model (an adaptation from Fish Bioenergetics 3.0, http://aqua.wisc.edu/publications). The model in the present study employs an adult individual that has reached its asymptotic size, so that all surplus energy goes to reproduction. The simulation period was 1 yr and addressed the optimal overwintering strategy in relation to investing foraging effort at the cost of mortality. The spawning date was fixed to January 1 (Macer 1966, Bergstad et al. 2001).

Energy gain was based on stomach size and evacuation rates, and energy losses were determined by the assimilation efficiency, standard metabolism and activity costs related to swimming. Temperature dependencies were included in the stomach evacuation rate and the standard metabolic cost.

The habitat was described as a 2-box system. The individual could either be in its refuge (which for a sandeel means being buried in the sediment), where predation mortality is low and food supply is zero, or in the pelagic zone (arena), where the individual can feed at the expense of higher predation mortality (including fishing mortality). During overwintering, the individual was permanently in its refuge. As sandeels also burrow in the seabed within the foraging window, during night time as well as during parts of the day (Winslade 1971), we resolved the model on daily time steps. However, physiology and diel behavioural patterns were related to hourly time scales after each daily time step, such that the individual in the model only spent time in the arena during daylight hours starting at sunrise and whilst the stomach was not full. Gut filling dynamics were therefore a function of prey availability, day length and gut evacuation. The energy uptake, energy expenditure and mortality that accumulated over the course of the year, as a result of a given foraging window, were combined into the lifetime reproductive index $R_{0}$ (an index for the numbers of offspring produced per lifetime; see Stearns 1992). The foraging window which gave the highest $R_{0}$ was considered the optimal foraging window. Individuals that chose an overwintering behaviour that would not let them accumulate enough energy to cover the energy costs during the simulation year died from starvation. Model parameters are summarised in Table 1.

Details of the model. Consumption: Within the foraging window, consumption $(C)$ on a given day $t$ was described as assimilated energy $(\mathrm{kJ})$ :

$$
C(t)=N(t) \cdot \varepsilon
$$

where $N(t)$ is the number of encountered (and ingested) prey items on day $t$ (see Eq. 5) and $\varepsilon$ is the caloric value $(\mathrm{kJ})$ of each prey item after accounting 
Table 1. Ammodytes marinus. Model parameterisation for a $13 \mathrm{~cm}$ sandeel. Parameterisation was based on our own experiments combined with a general assimilation efficiency (Ciannelli et al. 1998) and published data on calanoid copepods (Comita et al. 1966, Yamaguchi \& Ikeda 2000, Gentleman et al. 2008); see Supplement 1 at www.int-res.com/articles/suppl/m416p201_ supp.pdf for information about the source of each parameter

\begin{tabular}{|lclc|}
\hline Symbol & Unit & \multicolumn{1}{c|}{ Definition } & Value \\
\hline$\varepsilon$ & $\mathrm{kJ}$ & Assimilated caloric value of 1 prey item & $23.5 \times 10^{-4}$ \\
$V$ & Number of prey items & Stomach volume & 1860 \\
$a$ & - & Fitted coefficient in Eq. (4) & $-2.7 \times 10^{-2}$ \\
$b$ & - & Fitted coefficient in Eq. (4) & $-3.6 \times 10^{-3}$ \\
$R_{\mathrm{A}}$ & $\mathrm{kJ}$ & Isolated energetic cost of swimming $\mathrm{g}^{-1} \mathrm{~h}^{-1}$ & $34 \times 10^{-4}$ \\
$C$ & - & Fitted coefficient in Eq. (8) & $8 \times 10^{-5}$ \\
$d$ & - & Fitted coefficient in Eq. (8) & $25 \times 10^{-5}$ \\
$W$ & $\mathrm{~g}$ & Weight of the fish & 6 \\
$Z_{\mathrm{A}}$ & - & Hourly mortality in arena & varied \\
$Z_{\mathrm{R}}$ & - & Hourly mortality in refuge & varied \\
$f(t)$ & Prey encounter $\mathrm{h}^{-1}$ & Food regime as a function of day $t$ & varied \\
\hline
\end{tabular}

for assimilation efficiency and the metabolic cost associated with digestion, absorption and storage of nutrients. The number of prey that could potentially be encountered by the individual on day $t$ was determined by the availability of prey and the day length:

$$
N_{\text {enc }}(t)=f(t) \tau(t)
$$

where $\tau(t)$ is day length (h), and $f(t)$ is the food regime, and describes encounter rate on day $t$ (number of suitable prey encountered per hour). As a simplification, swimming velocity was assumed to be constant and is therefore not included in Eq. (2). The upper limit on the number of encountered prey per day was determined by available stomach volume at sunrise:

$$
N_{\max }(t)=V-S(t-1)+E
$$

where $V$ is volume or capacity of an empty stomach (numbers of prey items), $S(t-1)$ is the stomach fullness on day $t-1$ (numbers of prey items), and $E$ is what has been evacuated (numbers of prey items) since the previous day. As simulations in the present study were carried out for only a single size, the same $V$ was used in all simulations. In order to keep the computation simple, E was estimated in the following way at sunrise:

$$
E(h)=S(t-1)-\exp \{\ln [S(t-1)]+[a+b T(t)] h\}
$$

To avoid introducing a non-systematic bias to $E$, the extent of the time period during which the stomach was filling up on day $t-1$ was accounted for. Evacuation time $h$ is therefore the time (h) since the midpoint of the foraging period on day $t-1$, which was calculated here as $24-H(t-1) / 2$, where $H(t-1)$ is time spent foraging on day $t-1$, calculated using Eq. (6). By using this approach only a small systematic bias was introduced to $E$. $T(t)$ is a forcing function describing seasonality in water temperature, and $a$ and $b$ are fitted coefficients describing the temperature effect on stomach evacuation. Both $N_{\text {max }}$ and $N_{\text {enc }}$ are upper boundaries on the number of encountered prey. In our model, the actual number of encountered prey was therefore:

$$
N(t)=\min \left[N_{\text {enc }}(t), N_{\max }(t)\right]
$$

Behaviour: On a given day $t$, the individual was allowed to be in 1 of 2 states: foraging (daily shifts between arena and refuge) or overwintering (permanently in the refuge). Furthermore, the individual could only shift state twice during the year. In this way, behaviour on the annual time scale was condensed into 2 annual decisions, when to end overwintering and when to start overwintering, which when combined, comprised the timing and duration of the foraging window. A given overwintering scenario is described in the model by $\sigma$, which is a binary vector of length 365 corresponding to the $365 \mathrm{~d}$ of the year. $\sigma(t)=1$ if the individual, on day $t$, is foraging in the arena and $\sigma(t)=0$ if the individual is overwintering in the refuge.

To ensure that the individual did not spend unnecessary time in the arena (where mortality was high), but instead went to the refuge during the hours after sunset and when its stomach was full, the time in hours spent on day $t$ in the arena was:

$$
H(t)=\tau(t) \frac{N(t)}{N_{\text {enc }}(t)}
$$

Energetic cost: The daily metabolic cost $(R)$ is a function of the combined costs of standard metabolism and activity:

$$
R(t)=\left\{\begin{array}{lll}
R_{\mathrm{S}}(t) \cdot 24 w+w\left[R_{\mathrm{A}} \cdot H(t)\right] & \text { for } & \sigma(t)=1 \\
R_{\mathrm{S}}(t) \cdot 24 w & \text { for } & \sigma(t)=0
\end{array}\right.
$$

where $R_{\mathrm{S}}$ and $R_{\mathrm{A}}$ are the hourly standard metabolism and the activity metabolism, respectively, for $1 \mathrm{~g}$ of fish $(\mathrm{kJ})$, and $w$ is the weight of the fish $(\mathrm{g}) . R_{\mathrm{A}}$ is constant, whereas $R_{\mathrm{S}}$ depends on temperature:

$$
R_{\mathrm{S}}(t)=c T(t)-d
$$

where $c$ and $d$ are fitted coefficients. 
Mortality: The daily mortality $\left(Z_{\mathrm{d}}\right)$ was described by the time spent in the arena and the refuge:

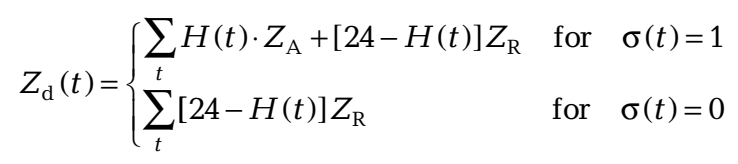

where $Z_{\mathrm{A}}$ and $Z_{\mathrm{R}}$ are hourly predation mortality in the arena and refuge, respectively $\left(Z_{\mathrm{A}}\right.$ could also include fishing mortality). From the daily mortality and the overwintering scenario $\sigma$, the probability of surviving $1 \mathrm{yr}$ is:

$$
P[\sigma]=\exp \left(-\sum_{t=1}^{365} Z_{\mathrm{d}}(t)\right)
$$

Fitness: If results of the equations for consumption (Eq. 1), energetic cost (Eq. 7) and mortality (Eq. 9) are summed over the entire year for a given overwintering scenario $\sigma$, the lifetime reproductive index $R_{0}$ can be calculated in the following way:

$$
R_{0}[\sigma]=\omega \frac{P}{1-P} \sum_{t=1}^{365}[C(t)-R(t)]
$$

where $\omega$ is the probability of surviving the larval and juvenile stage. As juvenile and adult life-stages are temporally separated, the juvenile and adult contribution to $R_{0}$ factorises in Eq. (11), and the influence of juvenile and adult life strategies on $R_{0}$ can be investigated independently. The sum of $C-R$ over the entire year is the annual surplus energy gain $(G)$ and is assumed to be proportional to individual fecundity. When the inter-annual variability in abiotic conditions is neglected, the reproductive output can explicitly be summed over the entire life span as in Eq. (11). It was assumed that population density affects the individual either by increased larval/juvenile mortality $(\omega)$ or by reducing annual surplus energy gain (competition). This corresponds to population density effects of class 1 and/or class 3 respectively in the classification of Mylius \& Diekmann (1995), and thereby optimisation of $R_{0}$ rigorously finds the overwintering scenario $\sigma$ that corresponds to the evolutionary stable strategy. This is a considerable simplification compared to explicitly including population density effects in the model. In the present study, $R_{0}$ is simply optimised with respect to $\sigma$ in order to predict the overwintering scenario that contains the optimal timing of the foraging window.

Forcing functions: The temperature forcing function applied to the model was a stylistic and general representation of the temperature cycle in the North Sea. The function is a cosine function:

$$
T(t)=T_{\min }+0.5\left(T_{\max }-T_{\min }\right)\left\{1-\cos \left[2 \pi\left(t+t_{\min }\right)\right]\right\}
$$

with minimum temperature of $5^{\circ} \mathrm{C}\left(T_{\min }\right)$ on January 31 $\left(t_{\min }\right)$ and a maximum temperature of $20^{\circ} \mathrm{C}\left(T_{\max }\right)$ on July 31 . Values of day lengths $\tau(t)$ correspond to the annual cycle on Dogger bank, North Sea.
The main time window for copepod production in the North Sea lasts for only a couple of months, with a steep increase in abundance peaking in late spring, at annual median temperatures, followed by a steep decline in abundance (Carlotti \& Radach 1996). A Gaussian distribution and a constant background food level was used to make a schematic representation of the food regime contained in the forcing function $f(t)$. The unit of $f(t)$ is number of prey encountered per hour. As a simplification, all suitable prey encountered were of uniform size (see Supplement 1). Unless stated otherwise, the background food level in the model (the food level that the fish experience in the model outside the zooplankton bloom in spring) provide the fish with just enough energy to sustain the energetic cost of foraging, i.e. even if the fish choose to forage in the arena during winter the daily energy budget will not become negative. The mean of the Gaussian distribution defines the timing of the peak in the zooplankton spring burst, the standard deviation (SD) defines the duration and increase/ decrease, and the space under the curve defines the intensity of the burst.

Model simulations: Eq. (11) was optimised with respect to $\sigma$ for various scenarios of predation mortality and food regimes. In order to investigate how food regime affects the optimal foraging window, $f(t)$ was manipulated either by changing the intensity or duration of the zooplankton spring burst, or the background food level. In order to investigate how predation mortality affects the optimal foraging window, Eq. (11) was optimised with respect to $\sigma$, for a range of $Z_{\mathrm{A}}$ (at 2 different $Z_{\mathrm{R}}: Z_{\mathrm{A}}$ ratios). Alternative mortality scenarios were also explored, in which daily mortality during the foraging period was either constant, i.e. not dependent on number of hours spent in the arena, or correlated with temperature, i.e. $Z_{\mathrm{A}}$. $\left(T_{\text {max }} / T_{\text {mean }}\right)$.

As the model was solved numerically, $R_{0}$ was calculated for all combinations of timing and duration of the foraging window. This made it possible to compare $R_{0}$ from suboptimal foraging windows with those from the optimal foraging window. This comparison was used to explore the fitness buffer capacity of an adaptive foraging window as opposed to a mal-adaptive or fixed foraging window.

Parameterisation: Model parameterisation was carried out for an adult female of length $13 \mathrm{~cm}$ and weight $6 \mathrm{~g}$, and was based on a combination of values from the literature and experimental studies conducted on Ammodytes tobianus as part of this study. A detailed description of the parameterisation and experimental measurements of stomach evacuation rate, stomach capacity, and swimming metabolism is given in Supplement 1, and Table 1 provides an overview of selected parameter values. 


\section{RESULTS}

The model was analysed both numerically and analytically. The sections below contain the numerical exploration with application to lesser sandeels. By imposing certain simplifications on the model, it was also possible to perform analytical exploration of the model; the highlights are presented here and the detailed analytical results are provided in Supplement 2 at www.int-res.com/articles/suppl/m416p201_supp. pdf. The aim of the analytical approach was to verify that the findings were not just the result of the chosen parameterisation but were valid in general, and to obtain a deeper insight into life strategy trade-offs.

\section{General patterns and the effect of elevating winter prey abundance (background food-level)}

The model predicted that the optimal foraging window was more or less symmetrically distributed around the Gaussian zooplankton spring burst curve, albeit considerably narrower (Figs. 1 to 3 ). The timing of the optimal foraging window remained more or less the same when winter prey abundance (background food level) supported a daily consumption of one third of the consumption during the zooplankton spring burst (Fig. 1C). The end and beginning of the overwintering period depended on a combination of the entire annual foraging history (including accumulation of mortality), and not on a threshold daily surplus energy gain. For example, when the zooplankton spring burst was spread out over a longer period, by increasing the standard deviation, the model predicted that sandeels will initiate the foraging window earlier (and end it later), and at lower daily surplus energy gain (Fig. 2).

Exactly how the optimal trade-off was determined between feeding- and mortality-related aspects was elucidated by mathematical analysis of Eq. (11). The analysis confirmed that the optimal foraging window was distributed symmetrically around the zooplankton spring burst (and the minor asymmetry explained by the phase lag between temperature and zooplankton productivity). Further, the analysis revealed that 2 fit-
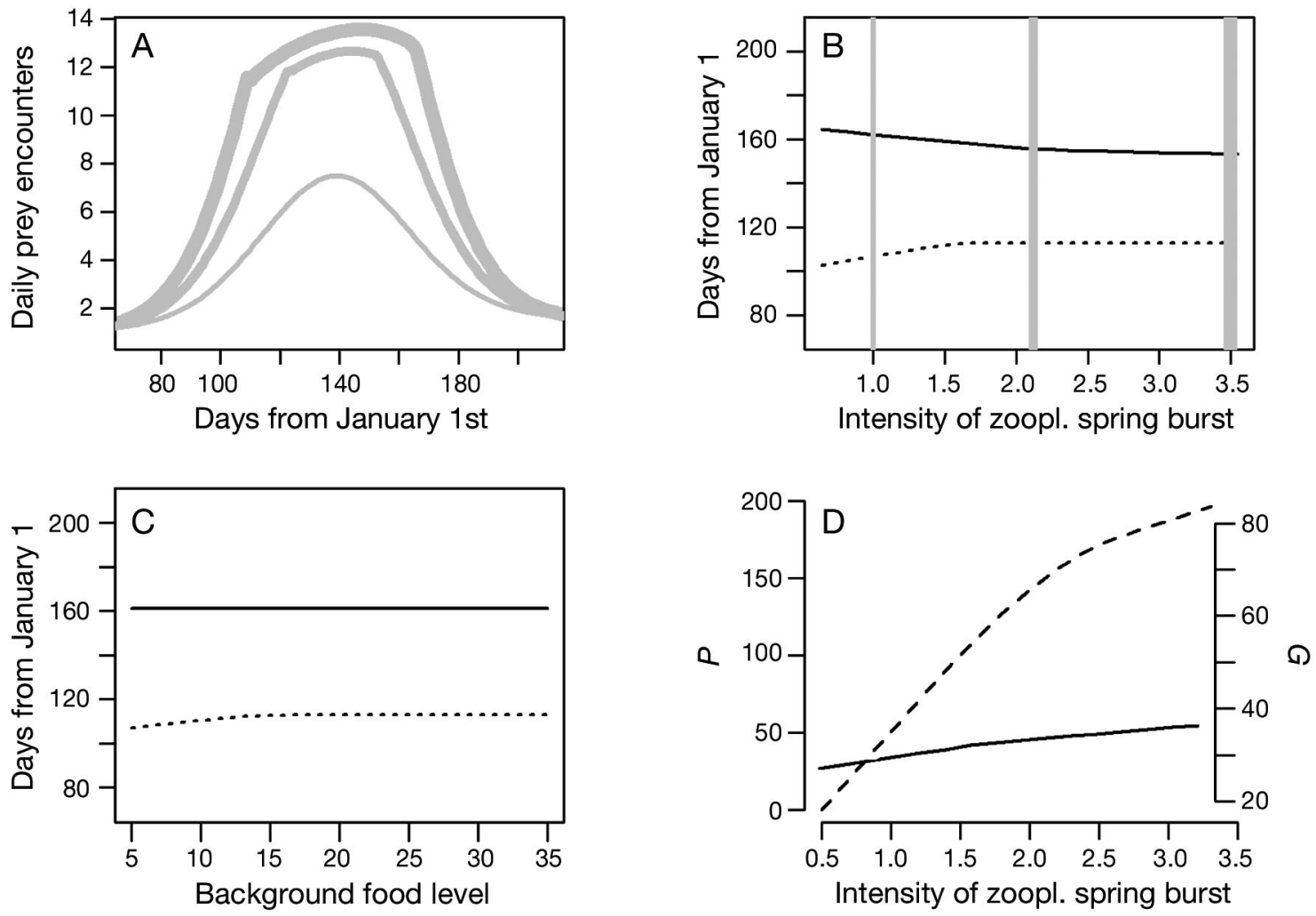

Fig. 1. Ammodytes marinus. Optimal foraging window in relation to food regime. (A) Daily total prey encounter (given in hundreds of prey items per day) for 3 different zooplankton spring burst intensities as a function of time of the year. (B) Onset (dotted) and offset (solid) of the optimal foraging window as a function of relative spring burst intensity. The vertical lines refer to the graphs in (A). (C) Onset (dotted) and offset (solid) of the optimal foraging window as a function of background food-level (values on the $x$-axis are the winter prey abundance relative to spring burst peak abundance, as \%). (D) Annual survival probability $(P$; solid) $(\%)$ and annual surplus energy gain $(G$; dashed) $(\mathrm{kJ})$ as a function of spring burst intensity. In all simulations an hourly arena mortality and refuge mortality of $1 \times 10^{-3}$ and $1 \times 10^{-5}$, respectively, were used 


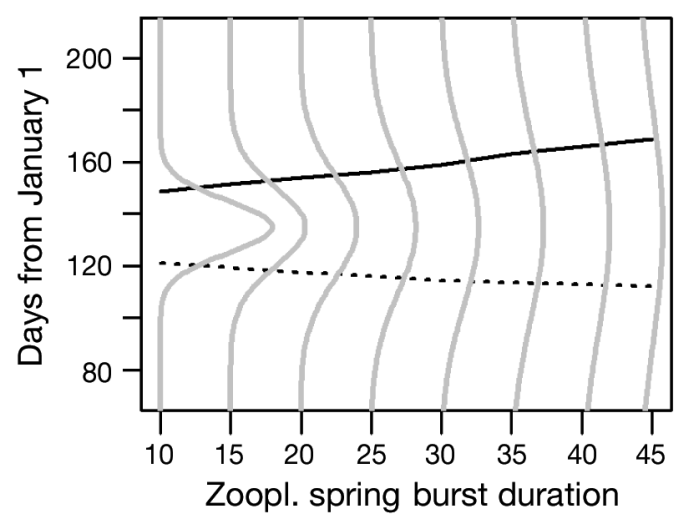

Fig. 2. Ammodytes marinus. Optimal foraging window in relation to the duration of the zooplankton spring burst. Onset (dotted) and offset (solid) of the optimal foraging window as a function of the zooplankton spring burst duration (in d) (represented by the SD of the Gaussian spring burst curve). The spring burst at $\mathrm{SD}=25$ corresponds to the medium prey encounter graph in Fig. 1A. For illustration purposes, the shapes of the spring bursts have been superimposed as thin grey lines. An hourly arena mortality and refuge mortality of $1 \times 10^{-3}$ and $1 \times 10^{-5}$, respectively, were used

ness regimes were possible. In Type 1 situations, $R_{0}$ always exhibits a single optimal overwintering period. Type 1 situations are characterised by a seasonal pattern, where consumption minus energetic cost of foraging is negative in a period during the winter. If consumption minus energetic cost of foraging is positive all
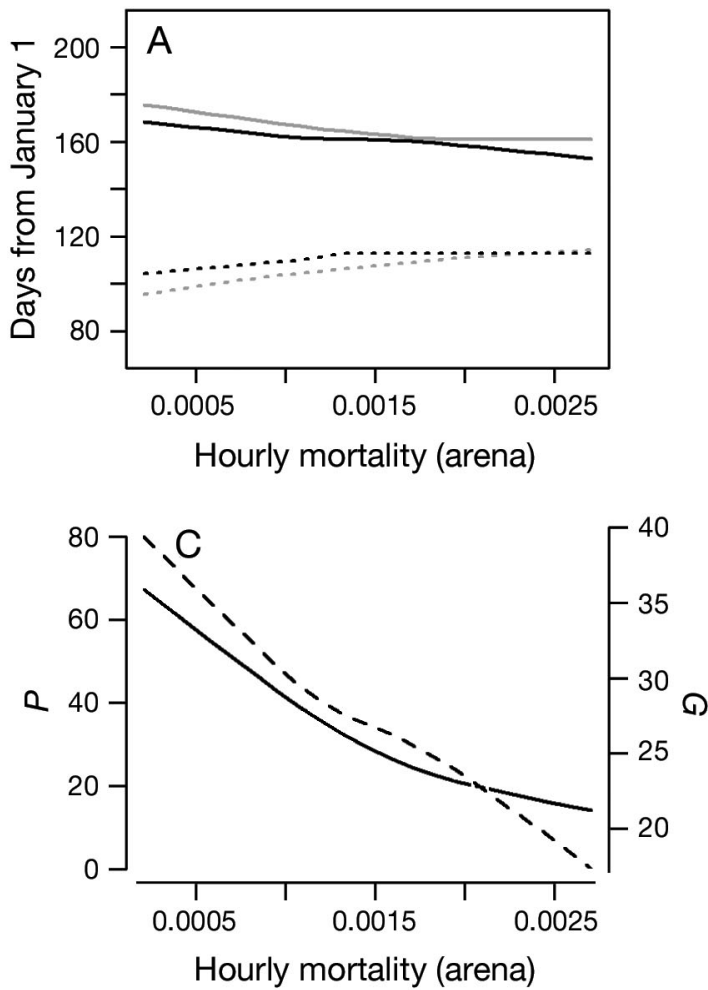

year round, it is a Type 2 situation, where it is possible that overwintering is skipped if the arena mortality $Z_{\mathrm{A}}$ is sufficiently low. We have not found Type 2 situations in biologically relevant parameter regimes for lesser sandeels in the North Sea, but they may exist for other species resembling the sandeel ecotype. Even though the model always predicts a single optimal overwintering period, the mathematical analysis also reveals a range of mortalities so high that fitness in the demographic equilibrium falls below 1 . This is due to the fish size-determined upper limits on fecundity; see Supplement 2 for technical details of the mathematical analysis.

\section{Effect of the intensity and duration of the zooplankton spring burst}

Reducing the duration or increasing the intensity of the zooplankton spring burst resulted in reduced duration of the optimal foraging window (Figs. 1B \& 2). However, there was a maximum level of spring burst intensity above which the optimal foraging window remained at a constant duration despite further increase in spring burst intensity (Fig. 1B). This maximum level was determined by daily total consumption shifting from being limited by prey encounter rate to being limited by stomach capacity and evacuation rate. At low intensities of zooplankton spring bursts the distribution of daily prey encounters followed the

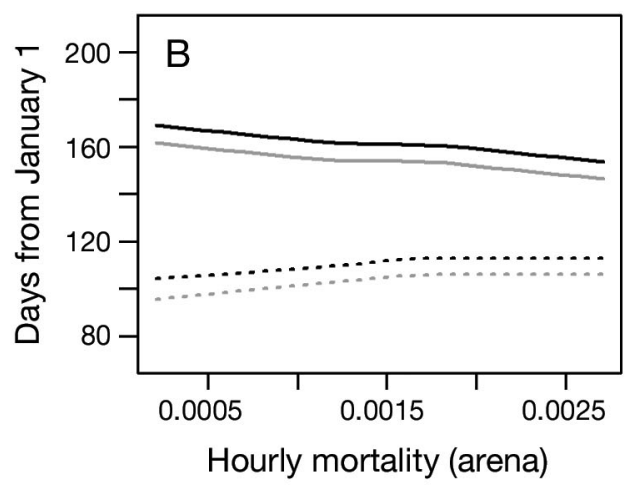

Fig. 3. Ammodytes marinus. Optimal foraging window in relation to predation mortality. (A) Onset (dotted) and offset (solid) of the optimal foraging window as a function of hourly mortality in the arena, for the default refuge-mortality:arena-mortality ratio $\left(Z_{\mathrm{R}} / Z_{\mathrm{A}}=0.01\right)$ (black) and $Z_{\mathrm{R}} / Z_{\mathrm{A}}=0.1$ (grey). (B) Effect of a temperature-scaled $Z_{\mathrm{A}}$ (grey) compared to the default scenario (black). (C) Annual survival probability in percentage $\left(P_{i}\right.$ solid), and annual surplus energy gain $(\mathrm{kJ})\left(G_{i}\right.$ dashed) as a function of $Z_{\mathrm{A}}$ for the default scenario. The zooplankton spring burst intensity used in all simulations corresponded to the medium prey encounter graph in Fig. 1A 
Gaussian spring burst curve, and hourly prey encounters was the limiting factor on consumption. However, at high burst intensities consumption became limited by stomach evacuation $(E)$ and day length $(\tau)$, thus the full potential of the spring burst was not utilised (note the flat top on the upper 2 curves in Fig. 1A).

Increased intensity of the zooplankton spring burst resulted in increased surplus energy gain $(G)$ and survival probability $(P)$ values. However, $G$ levelled off when daily total consumption became limited by stomach capacity (Fig. 1D,B). In the lower range of spring burst intensities, the increase in $P$ was due to the reduction in the duration of the optimal foraging window. In contrast, in the upper range of spring burst intensities, an increase in $P$ was caused by the high prey abundance leading to a reduction in the number of hours spent in the arena per day (Fig. 4B; note the dip in hours spent foraging per day; black dash-dotted line).
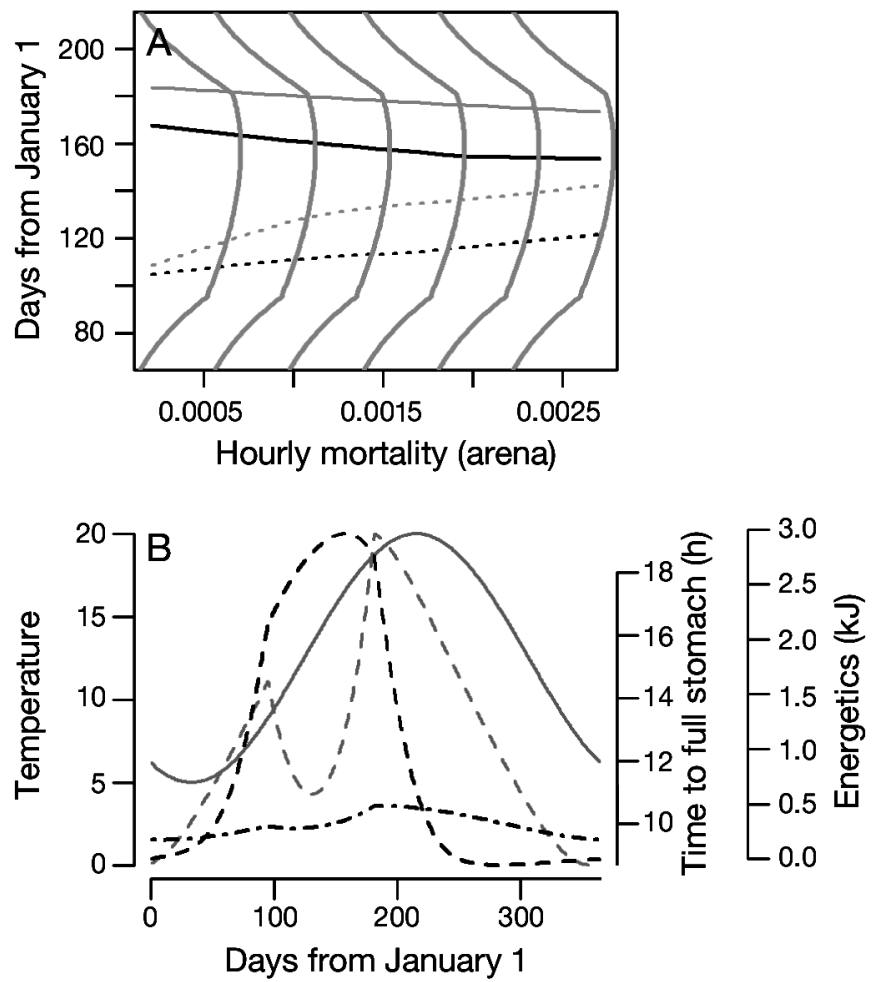

Fig. 4. Ammodytes marinus. Behavioural and physiological control of the optimal foraging window during a high intensity and long-lasting zooplankton spring burst. (A) Onset (dotted lines) and offset (solid lines) of the optimal foraging window as a function of hourly mortality in the arena $\left(Z_{\mathrm{A}}\right)$ for the default scenario (black) and a scenario in which daily mortality is constant $\left(12 \times Z_{\mathrm{A}}\right)$ and is thereby independent of the number of hours spent foraging in the arena (grey). Hourly arena mortality $=1 \times 10^{-3}$; hourly refuge mortality $=1 \times 10^{-5}$. (B) Water temperature $\left({ }^{\circ} \mathrm{C}\right)$ (solid grey); time spent in the arena per day (h) (grey dashed); daily surplus energy uptake (kJ) (black dashed); daily metabolic cost of foraging including standard metabolic cost (kJ) (black dash-dotted)

\section{Effect of mortality}

The duration of the optimal foraging window depended on mortality in both the arena and refuge. An increase in $Z_{\mathrm{A}}$ resulted in a decrease in the duration of the optimal foraging window. In contrast, the duration of the optimal foraging window increased slightly when $Z_{\mathrm{R}} / Z_{\mathrm{A}}$ was increased from 0.01 to 0.1 (Fig. 3A), and the onset and offset shifted to earlier in the year, by approximately $1 \mathrm{wk}$, when $Z_{\mathrm{A}}$ was scaled with temperature (Fig. 3B). The reduction in $P$ following elevated arena mortality was highest in the lower range of arena mortality and levelled off toward the upper range (Fig. 3C). In contrast, $G$ decreased more or less steadily as arena mortality increased.

\section{Daily processes of importance}

When the zooplankton spring burst intensity was high, the top of the distribution of daily surplus energy uptake became flat and slightly tilted (Fig. 1A). The daily processes involved were explored more thoroughly in a scenario of a long lasting, high intensity spring burst. The foraging window was centred symmetrically on the zooplankton spring burst and was considerably narrower than the flat tilted top of daily surplus energy uptake (Fig. 4A).

Warmer water increased metabolism as well as stomach evacuation rate (Fig. 4B), and in combination with increasing day length, the daily energy uptake more than outweighed the expense of increased metabolism. Based on this, one may expect that the optimal foraging window should be shifted to later in the year. However, the individual also spent more hours foraging in the arena as days became longer (Fig. 4B, grey dashed line), which in turn increased the daily accumulated mortality and, therefore, shifted the optimal foraging window to earlier in the year. This is illustrated by comparing the default scenario (Fig. 4A, black line) to a scenario where daily mortality is constant instead of being dependent on the hours spent foraging (Fig. 4A, grey line).

\section{Fitness buffer capacity and mismatch between foraging window and zooplankton spring burst}

We calculated $R_{0}$ for the optimal foraging window for both a high and a low zooplankton spring burst intensity (using intermediate $Z_{\mathrm{A}}$ ). We then either shifted timing of the foraging window (Fig. 5A) or reduced/ expanded it (Fig. 5B) and calculated the associated values of $R_{0}$. We found that a $14 \mathrm{~d}$ mismatch between the centre of the foraging window and the peak of a 

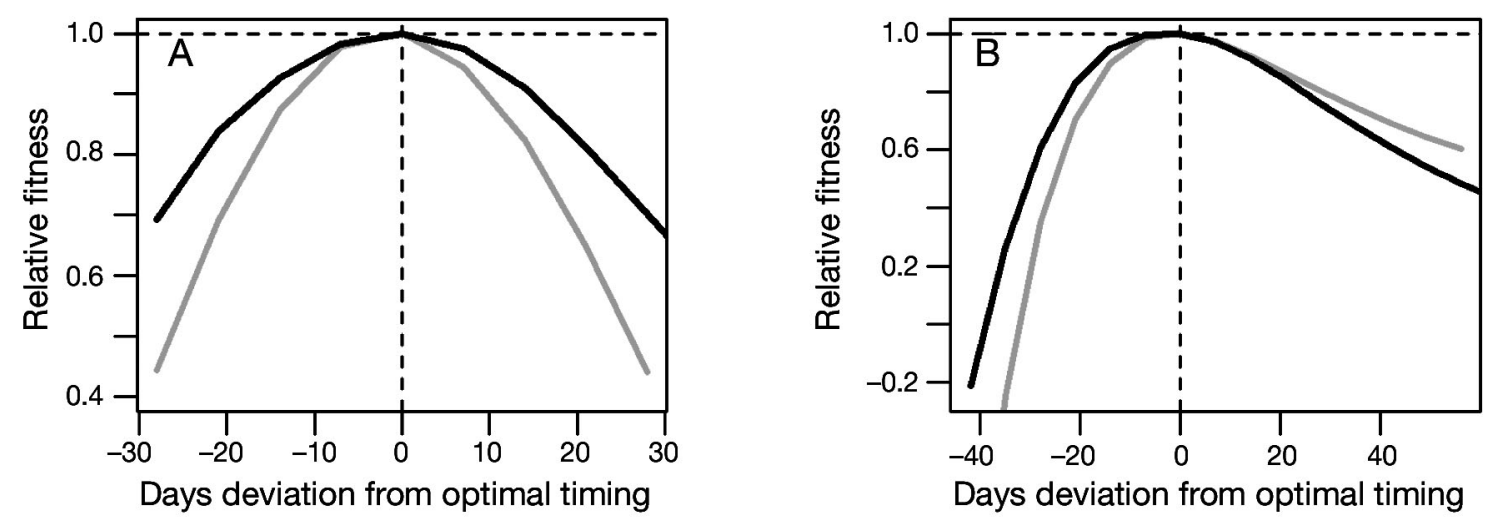

Fig. 5. Ammodytes marinus. Fitness buffer capacity in relation to mismatch between foraging window and zooplankton spring burst. (A) Fitness (plotted as relative values) as a function of translocation in time of the foraging window relative to the optimal foraging window. (B) Relative fitness as a function of expansion/contraction of the foraging window relative to the optimal duration of the foraging window. The exercise was carried out for 2 scenarios: A low intensity spring burst (grey) (corresponding to the lowest daily prey encounter graph in Fig. 1A) and a high intensity spring burst of relatively long duration (black) (corresponding to the highest daily prey encounter graph in Fig. 1A). In all simulations an hourly arena mortality and refuge mortality of $1 \times 10^{-3}$ and $1 \times 10^{-5}$, respectively, were used

low intensity spring burst (in either direction) resulted in $\sim 20 \%$ reduction in $R_{0}$, and a 25 d mismatch resulted in $\sim 50 \%$ reduction in $R_{0}$ (Fig. $5 \mathrm{~A}$ ). The fitness loss of a temporal mismatch was lower for the high burst intensity (Fig. 5A). Both contraction and expansion relative to the optimal foraging window also resulted in notable reduction of $R_{0}$. High contraction of the foraging window eventually lead to negative fitness, which means that the metabolic cost of overwintering exceeded surplus energy gain during the foraging period.

\section{Fitness buffer capacity and changes in predation mortality and zooplankton spring burst intensity}

We calculated $R_{0}$ for the optimal foraging window. We then changed $Z_{\mathrm{A}}$ and compared the $R_{0}$ for the case of a fixed foraging window, where the individual maintained the foraging window that was optimal in the initial scenario, to the case where the individual adapted the foraging window to the changes in $Z_{\mathrm{A}}$. We found that the advantage for the individual adapting the foraging window was inconsequentially small. This exercise is illustrated in Fig. 6A. The same type of exercise was repeated, but this time the intensity of the zooplankton spring burst was changed instead of predation mortality. We again found that the advantage for the individual adapting the foraging window was small (Fig. 6A,B). The main exception to this pattern was where the initial scenario was one of relatively high spring burst intensity (Fig. 6C). In this case, the individual adapting the foraging period was notably better than the individual that failed to adapt when spring burst intensity decreased.

\section{DISCUSSION}

To facilitate an investigation of the energy/predation trade-off in the context of the overwintering strategy of sandeel ecotypes, we developed a simple model framework that linked behaviour, mortality and bioenergetics. We demonstrated that the optimal solution to these 2 decisions was determined by an energy/predation trade-off, and found that the overwintering strategy remained the optimal strategy even when winter prey availability supported the energetic cost of foraging many times. We also found that food regime and hourly mortality affected the timing of the optimal foraging window.

In the present work, we did not include interannual variability in abiotic conditions, as we wished to understand the link between regimes of abiotic conditions and differences in the optimal overwintering period, with the aim of understanding local adaptations as well as expected responses to anthropogenic and climate changes. Furthermore, timing of the spawning window was fixed at January 1 in the present work assuming it to be determined solely by hydrographical properties ensuring maximal larval retention rates. A complete life history investigation should also consider optimisation of the spawning window and inter-annual variability in abiotic conditions; because an optimal life strategy corresponding to an average regime of abiotic conditions may become suboptimal when facing inter-annual fluctuations. Our model can certainly be extended to include stochastic fluctuations, thereby addressing a stochastic optimisation problem, but this is beyond the scope of the present work. 

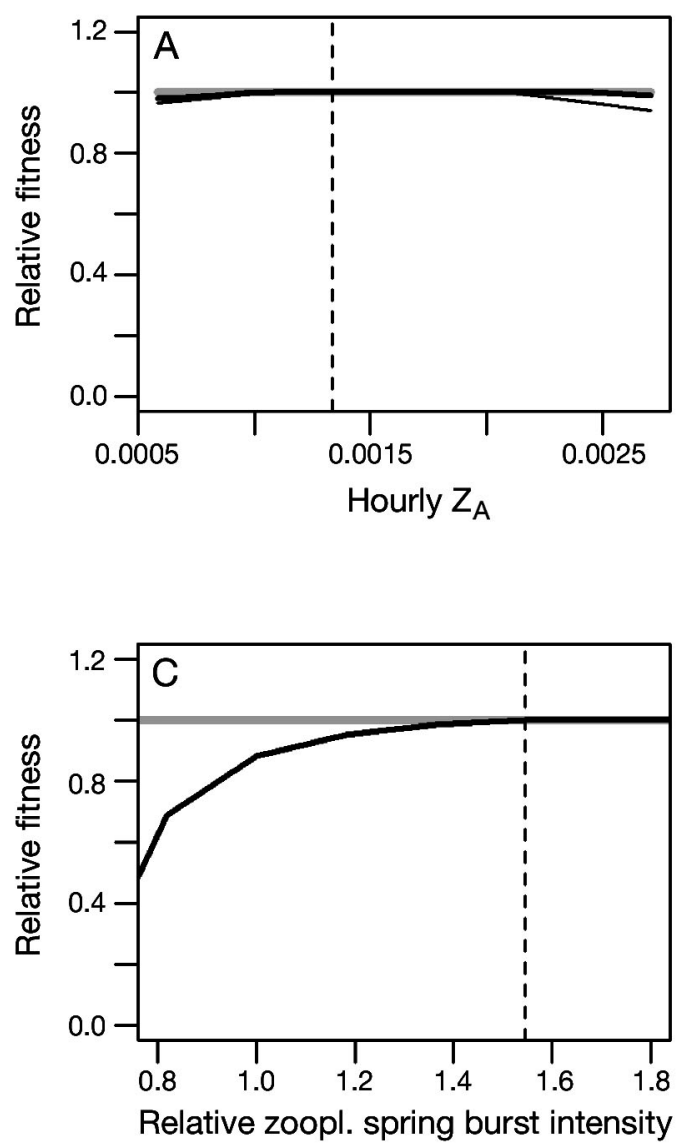

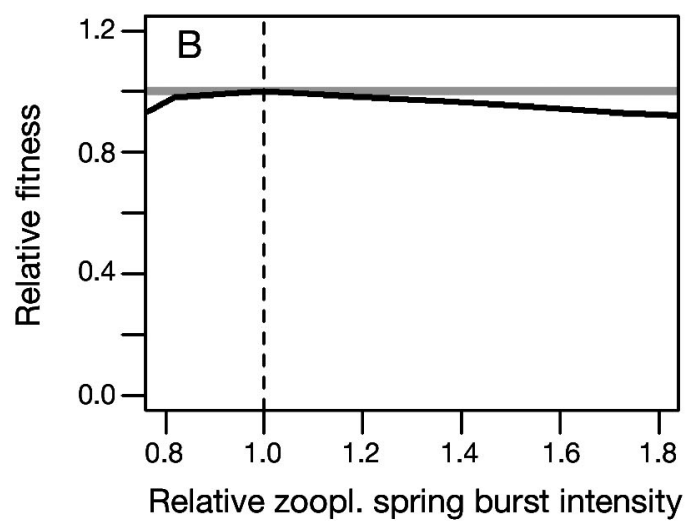

Fig. 6. Ammodytes marinus. Fitness buffer capacity in relation to changes in predation mortality and zooplankton spring burst intensity. Fitness (plotted as relative values) as a function of (A) hourly mortality in the arena and $(B, C)$ spring burst intensity for an adaptive case where the foraging window is adapted optimally (grey) and for a fixed case where the foraging window is held fixed while spring burst intensity or mortality is varied (black). The vertical dashed line is the starting point at which the foraging window of the fixed case is optimal. This starting point is the only difference between (B) and (C). In (A), the exercise was carried out for low spring burst intensity (thin black line) (corresponding to the lowest daily prey encounter graph in Fig. 1A) and high spring burst intensity (thick black line) (corresponding to the highest daily prey encounter graph in Fig. 1A). The ranges of spring burst intensities in (B) and (C) correspond to the range used in Fig. 1B. An hourly arena mortality $\left(Z_{\mathrm{A}}\right)$ of $1 \times 10^{-3}$ was used in $(\mathrm{B})$ and $(\mathrm{C})$ and an hourly refuge mortality of $1 \times 10^{-5}$ was used in (A), (B) and (C). Note: $Z_{\mathrm{A}}=1 \times 10^{-3}$ results in an annual mortality that roughly corresponds to the annual mortality applied in the North Sea sandeel assessment (ICES 2007)

\section{Model output in relation to available information on lesser sandeels}

Lesser sandeels make both seasonal and diurnal shifts between the pelagic feeding arena and being buried in the sandy sediments. Commercial landing data strongly suggest that the seasonal foraging window for adults lasts for only 2 to 4 mo during spring, with a peak in activity around May. This distinct pattern is reflected in both the fishery and in the diets of their predators (Macer 1966, Winslade 1974a, Reeves 1994, MacLeod et al. 2007). The timing and extent of the foraging window seem to vary slightly from year to year and from region to region (Macer 1966, Winslade 1974a, Reeves 1994, Sharples et al. 2009). Furthermore, lesser sandeel juveniles (mainly age-0 and age-1) have a prolonged feeding period compared to adults (Macer 1966, Reeves 1994, Hamer et al. 2000, Kvist et al. 2001). This pattern finds further support in a study of the sandeel-eating shag Phalacrocorax aristotelis, which showed that intense feasting on sandeel continued until at least October in years where juvenile sandeels were the most abundant item in the diet, whereas in years where adult sandeel dominated the diet, feeding activity concentrated around April (Harris \& Wanless 1991). It has been suggested that prey concentrations, light intensity, day length and temperature determine the shifts between overwintering period and foraging period (Winslade 1974a,b,c).

In agreement with the published data, the general trends that emerged from the present model simulations predicted that adult lesser sandeels should only forage during the peak period of the zooplankton spring burst and spend the rest of the year overwintering submerged in the seabed. Simulations were based on general and schematic representations of temperature and prey availability, as the main aim of the study was to understand the generic links between the seasonal environment and overwintering from an energy/predation perspective, rather than attempting to forecast geographical patterns in the North Sea. However, Winslade (1974a) presented data for the southern North Sea of monthly prey availability, sea temperature and commercial sandeel landings from before the sandeel fishery became strictly regulated by quotas and seasonal constraints. When these environ- 
mental data were used in the model the predicted foraging window enveloped $70 \%$ of total sandeel landings (Fig. 7).

In the present study a constant hourly arena mortality of approximately $1 \times 10^{-3}$ (and a refuge mortality vs. arena mortality ratio of $1 \times 10^{-2}$ ) was used in all analyses where mortality was kept constant. At this level of hourly mortality, the model estimated annual survival probability to be roughly $50 \%$, which resembles the annual mortality of 0.6 estimated for lesser sandeels in the North Sea for age 2 and older (ICES 2007). In reality, daily predation risk presumably fluctuates over the year. Firm measures of intra-annual fluctuations in mortality were not available, and inclusion of a submodel of seasonal variation in mortality would involve a detailed analysis of the evolutionary processes related to the close interactions and multiple feedback pathways between prey and predator(s) as well as the assemblage of alternative prey from which the predators can choose at a given time of the year. This was therefore not considered to be within the scope of the present study. However, as roughly $90 \%$ of the predators on lesser sandeels in the North Sea are poikilotherms (Furness 2002), a first step towards introducing seasonal variation in mortality to the model would be to assume that mortality due to consumption of sandeel by fish predators is limited by the temperature-dependent stomach evacuation rate of the predator. Results presented here suggest that scaling mortality with temperature has a slight effect on the outcome of the model as it moves the foraging window to slightly earlier in the year.

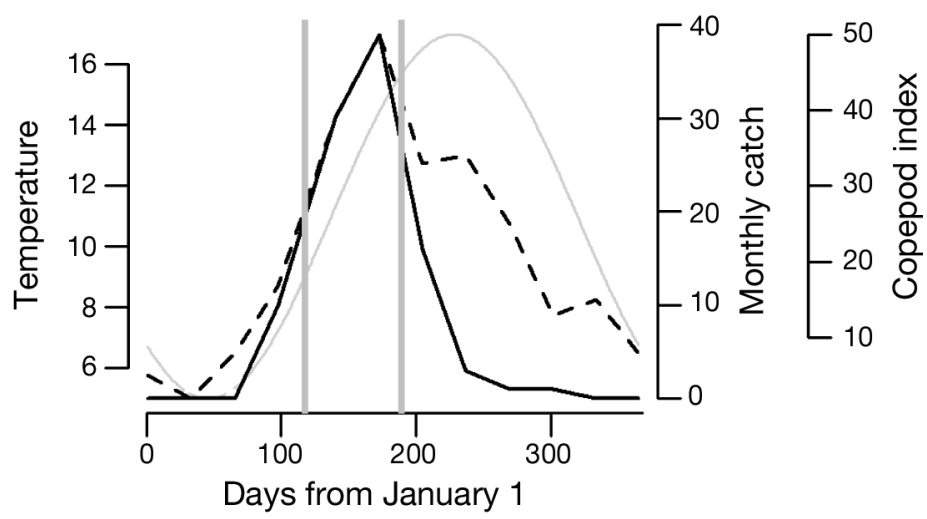

Fig. 7. Ammodytes marinus. Onset and offset (vertical grey lines) of the optimal foraging window compared to monthly North Sea sandeel catches from before the fishery became strictly regulated. Catch data (black solid line; percentage of total annual catch), temperature (grey solid line; ${ }^{\circ} \mathrm{C}$ ) and copepod index (dashed line; number of copepods per sample) reported by Winslade (1974a) were used to force the model (the original copepod data are from Colebrook \& Robinson 1961). Before using the copepod index in the model, values were raised so that peak abundance in June corresponded to a daily total prey encounter of 700 . Annual survival probability was $50 \%$, which resembles the mortality applied by ICES for adult sandeels
The total energy content of a $13 \mathrm{~cm}$ lesser sandeel in July-August is approximately $50 \mathrm{~kJ}$, and $85 \mathrm{~kJ}$ for a $15 \mathrm{~cm}$ lesser sandeel (Hislop et al. 1991, Pedersen \& Hislop 2001). Assuming that $60 \%$ of this energy can be mobilised (Hislop et al. 1991), these values conform to the values of annual surplus energy gain predicted for sandeel at the lower range of zooplankton spring burst intensities (or high population densities leading to intra-specific competition for food).

\section{Energy/predation trade-off in general}

The majority of previous studies of the energy/predation trade-off in fish, and animals in general, have focused on short-term processes (daily or hourly timescales, as opposed to the annual time-scale addressed in the present study) such as diel vertical migration, and ontogenetic or state-dependent diurnal decisions regarding habitat choice and foraging activity (e.g. Lima \& Dill 1990, Houston et al. 1993, Burrows 1994, Railsback et al. 1999, Biro et al. 2003, 2006). Those studies show that the optimal behavioural response to increased predation mortality is to reduce foraging activity, given that foraging activity is proportional to the mortality and a critical minimum energy uptake is not compromised. This agrees with our predictions, despite the difference in the time-scale at which the trade-off was addressed. Fish studies investigating the energy/predation trade-off on an annual time-scale are much rarer. A field study utilising data from passive integrated transponder (PIT)-tagged roach Rutilus rutilus and their main predators (Esox lucius and Perca fluviatilis) indicated that roach make seasonal migrations between habitats in order to minimise the ratio between predation mortality and growth rate (Brönmark et al. 2008). Related model studies have focussed on diel vertical migration of copepods using a state-dependent approach and dynamic programming framework to identify the optimal annual behavioural and reproductive strategy (e.g. Fiksen \& Carlotti 1998). Dynamic programming techniques are, in many ways, a more advanced approach to solving complex optimality problems. However, it is also far more difficult to interpret the results from such models, and a comparison of the fitness from the optimal strategy to that of suboptimal strategies is difficult if not impossible to conduct. Furthermore, by imposing certain simplifications, it was possible to solve the present type of model conceptually and analytically. This helps to identify which features and properties of the results are generic and whether other types of results are possible. 


\section{Daily processes}

Using a mechanistic model of the ingestion rate of Norwegian spring-spawning herring Clupea harengus, Varpe \& Fiksen (2010) show that high latitude seasonality in day length and light regimes may be more important in determining the onset of the foraging window than the exact timing of the zooplankton spring burst. A similar pattern arose from the present model. Here, hourly prey encounters reached their seasonal maximum when the spring burst peaked. However, water temperature and stomach evacuation rate were still low and day length still relatively short. Maximum daily total consumption was therefore reached later than the peak in the zooplankton spring burst. The question of whether it is better to forage during times when total daily consumption is maximised or during times when the hourly prey encounters are maximised therefore depends on whether daily mortality is constant or proportional to hours spent foraging. If daily mortality is proportional to the number of hours spent foraging (which is how the model here implemented mortality in the default settings), then the daily mortality becomes inversely proportional to the hourly prey encounters as long as maximum stomach capacity is not reached. However, when consumption shifted from being limited by prey encounter rate to being limited by stomach evacuation rate, daily mortality became dependent upon day length. It seems reasonable to assume that daily mortality is proportional to hours spent foraging. It could however be speculated that sandeels are more vulnerable during the emerging and burying phases, and during the vertical migration in the morning and afternoon/evening, as indicated by some field observations (Hobson 1986, Darbyson et al. 2003, Temming et al. 2004, Engelhard et al. 2008).

\section{Behavioural plasticity and fitness benefits of adapting to environmental changes}

Behavioural plasticity can be a result of adaptations to local environmental conditions driven by natural selection of genotypes in the population (adaptations on the population level) or can be a result of phenotypic plasticity (adaptations on the individual level) (e.g. Via \& Lande 1985, Kawecki \& Ebert 2004). In contrast, when the individual perceives its surroundings, processes the information, and acts accordingly and momentarily, we often use the term adaptive decisionmaking instead (e.g. Lima 1998).

We know that a range of behaviours may have fitness comparable to that of the optimal behaviour (Mangel 1991). In the present study, we found that the fitness-related advantage of adapting the timing of the foraging window to differences in predation mortality (and/or fishing mortality) is very small, even when mortality during the foraging period increases or decreases many-fold. The minor fitness advantage of adapting indicates that, at the population level, adaptations to local environmental conditions are possible only if mortality rate is relatively stable on an evolutionary time-scale.

The fitness-related incentive for an adaptive response to differences in zooplankton spring burst intensities (or intra-specific competition for food) was not entirely clear. Even though there seemed to be a considerable fitness-related advantage of adapting overwintering behaviour according to a decrease in spring burst intensity, the relative advantage of adapting to an increase in spring burst intensity was very small. It therefore seems reasonable to assume that the optimal behaviour during low spring burst intensities is a stable optimal strategy. However, it may be that with very high consumption, reserves and growth become saturated and sandeels would benefit, in terms of fitness, from starting the overwintering phase earlier than predicted by the model.

The present study showed that inability to adjust the timing of the foraging window to variation in the timing of the zooplankton spring burst would have a large negative effect on fitness. Expanding the foraging window to increase the probability of capturing the spring burst and thereby avoid mismatch is not an optimal solution to the problem, since fitness decreased rapidly when the foraging window covered periods outside the spring burst, including its tail end. Considering this large fitness-related incentive of adapting the foraging window to the spring burst timing, it seems possible that local adaptations or phenotype plasticity could have evolved. For adaptive decisionmaking to have evolved, the individual needs ways to perceive the advancement of the spring burst and its fading out. The existence of such abilities remains an open question.

\section{Perspectives}

The lethal aspects of predator-prey interactions, and their implications for population dynamics and ecosystems, are indisputably crucial and relatively well understood. However, the implications and quantitative importance of behaviourally mediated population responses of predator-prey interactions, the non-lethal aspects, are still poorly understood (Lima \& Dill 1990, Lima 1998, Dill et al. 2003). From this perspective, the simple type of model framework presented here offers an analytical tool to interpret observations and formu- 
late testable hypotheses regarding the overwintering strategy and zooplankton burst-directed foraging activity. The model produced general patterns of behaviour, bioenergetics and mortality related to lesser sandeels in the North Sea, while at the same time illustrating how sandeels trade off energy gain maximisation for mortality reduction on an annual time-scale.

An important finding was that the precise level of mortality and energy gain rates had little influence on the foraging activity level. However, this does not imply that predation mortality and anticipated energy gain do not influence the behaviour of lesser sandeels. On the contrary: the cost of predation related to foraging activity is what led to the predictions that all foraging activity should strictly coincide with the peak period of the zooplankton spring burst. Inter-annual shifts in the timing of the spring burst could therefore cause the size of succeeding year-classes and spawning stock size to fluctuate, in particular when the population is below carrying capacity.

The notion that timing and intensity of the zooplankton spring burst have substantial effects on population dynamics of lesser sandeels has recently been proposed in a study on the timing of reproductive allocation in this species (Boulcott \& Wright 2008). It is also known that spring burst timing exhibits regional differences, inter-annual fluctuations and climateinduced long-term shifts within ecosystems populated by sandeels (e.g. Brander 1994, Edwards \& Richardson 2004, Greenstreet et al. 2006, Sharples et al. 2006). Understanding how sandeels, as a key mid-trophic species and an important commercial resource, cope with this variability is essential for understanding population dynamics both in the present time and in projections of climate change scenarios. We propose that the type of model presented here can play a role in this context, although we admit that focused field studies are required to confirm for example the adaptive capabilities of sandeel.

Acknowledgements. We thank Prof. J. Fleng Steffensen for providing laboratory facilities, and students J. Kring Højgaard and J. Møller for assistance in the laboratory. This research was supported by FISHNET, SLIP, MODREC and SUNFISH.

\section{LITERATURE CITED}

Bergstad OA, Hoines AS, Kruger-Johnsen EM (2001) Spawning time, age and size at maturity, and fecundity of sandeel, Ammodytes marinus, in the north-eastern North Sea and in unfished coastal waters off Norway. Aquat Living Resour 14:293-301

Biro PA, Post JR, Parkinson EA (2003) Population consequences of a predator-induced habitat shift by trout in whole-lake experiments. Ecology 84:691-700

Biro PA, Post JR, Abrahams MV (2005) Ontogeny of energy allocation reveals selective pressure promoting risk-taking behaviour in young fish cohorts. Proc Biol Sci 272: 1443-1448

Biro PA, Abrahams MV, Post JR, Parkinson EA (2006) Behavioural trade-offs between growth and mortality explain evolution of submaximal growth rates. J Anim Ecol 75: 1165-1171

> Biro PA, Post JR, Booth DJ (2007) Mechanisms for climateinduced mortality of fish populations in whole-lake experiments. Proc Natl Acad Sci USA 104:9715-9719

> Boulcott P, Wright PJ (2008) Critical timing for reproductive allocation in a capital breeder: evidence from sandeels. Aquat Biol 3:31-40

$>$ Brander KM (1994) The location and timing of cod spawning around the British-Isles. ICES J Mar Sci 51:71-89

Brêthes JF, Saint-Pierre R, Desrosiers G (1992) Growth and sexual maturation of the American sandlance (Ammodytes americanus Dekay) off the north shore of the Gulf of St. Lawrence. J Northwest Atl Fish Sci 12:41-48

Brönmark C, Skov C, Brodersen J, Nilsson PA, Hansson L (2008) Seasonal migration determined by a trade-off between predator avoidance and growth. PLoS ONE 3: e1957

Burrows MT (1994) An optimal foraging and migration model for juvenile plaice. Evol Ecol 8:125-149

Carlotti F, Radach G (1996) Seasonal dynamics of phytoplankton and Calanus finmarchicus in the North Sea as revealed by a coupled one-dimensional model. Limnol Oceanogr 41:522-539

Christensen A, Jensen H, Mosegaard H, John MS, Schrum C (2008) Sandeel (Ammodytes marinus) larval transport patterns in the North Sea from an individual-based hydrodynamic egg and larval model. Can J Fish Aquat Sci 65: 1498-1511

Ciannelli L, Brodeur RD, Buckley TW (1998) Development and application of a bioenergetics model for juvenile walleye pollock. J Fish Biol 52:879-898

Colebrook JM, Robinson GA (1961) The seasonal cycle of plankton in the North Sea and the North-Eastern Atlantic. J Cons Int Explor Mer 26:156-165

Comita GW, Marshall SM, Orr AP (1966) On the biology of Calanus Finmarchicus. XIII. Seasonal change in weight, calorific value and organic matter. J Mar Biol Assoc UK 46: $1-17$

Darbyson E, Swain DP, Chabot D, Castonguay M (2003) Diel variation in feeding rate and prey composition of herring and mackerel in the southern Gulf of St Lawrence. J Fish Biol 63:1235-1257

Dill LM, Heithaus MR, Walters CJ (2003) Behaviorally mediated indirect interactions in marine communities and their conservation implications. Ecology 84:1151-1157

> Edwards M, Richardson AJ (2004) Impact of climate change on marine pelagic phenology and trophic mismatch. Nature 430:881-884

> Engelhard GH, van der Kooij J, Bell ED, Pinnegar JK, Blanchard JL, Mackinson S, Righton DA (2008) Fishing mortality versus natural predation on diurnally migrating sandeels Ammodytes marinus. Mar Ecol Prog Ser 369: 213-227

Fiksen Ø, Carlotti F (1998) A model of optimal life history and diel vertical migration in Calanus finmarchicus. Sarsia 83:129-147

> Frederiksen M, Wright PJ, Harris MP, Mavor RA, Heubeck M, Wanless S (2005) Regional patterns of kittiwake Rissa tridactyla breeding success are related to variability in sandeel recruitment. Mar Ecol Prog Ser 300:201-211

Furness RW (1990) A preliminary assessment of the quantities 
of Shetland sandeels taken by seabirds, seals, predatory fish and the industrial fishery in 1981-83. Ibis 132: 205-217

Furness RW (2002) Management implications of interactions between fisheries and sandeel-dependent seabirds and seals in the North Sea. ICES J Mar Sci 59:261-269

Gauld JA (1990) Movements of lesser sandeels (Ammodytes marinus Raitt) tagged in the northwestern North Sea. J Cons Int Explor Mer 46:229-231

Gentleman WC, Neuheimer AB, Campbell RG (2008) Modelling copepod development: current limitations and a new realistic approach. ICES J Mar Sci 65:399-413

> Greenstreet SPR, Armstrong E, Mosegaard H, Jensen H and others (2006) Variation in the abundance of sandeels Ammodytes marinus off southeast Scotland: an evaluation of area-closure fisheries management and stock abundance assessment methods. ICES J Mar Sci 63:1530-1550

Hain JHW, Ellis SL, Kenney RD, Clapham PJ, Gray BK, Weinrich MT, Babb IG (1995) Apparent bottom feeding by humpback whales on Stellwagen Bank. Mar Mamm Sci 11:464-479

> Hamer KC, Phillips RA, Wanless S, Harris MP, Wood AG (2000) Foraging ranges, diets and feeding locations of gannets Morus bassanus in the North Sea: evidence from satellite telemetry. Mar Ecol Prog Ser 200:257-264

$>$ Harris MP, Wanless S (1991) The importance of the lesser sandeel Ammodytes marinus in the diet of the shag Phalacrocorax aristotelis. Ornis Scand 22:375-382

- Hislop JRG, Harris MP, Smith JGM (1991) Variation in the calorific value and total energy content of the lesser sandeel (Ammodytes marinus) and other fish preyed on by seabirds. J Zool 224:501-517

$>$ Hobson ES (1986) Predation on the Pacific sand lance, Ammodytes hexapterus (Pisces, Ammodytidae), during the transition between day and night in southeastern Alaska. Copeia 223-226

Houston AI, McNamara JM (1999) Models of adaptive behaviour. Cambridge University Press, Cambridge

> Houston AI, McNamara JM, Hutchinson JMC (1993) General results concerning the trade-off between gaining energy and avoiding predation. Philos Trans R Soc Lond B Biol Sci 341:375-397

Hurst TP (2007) Causes and consequences of winter mortality in fishes. J Fish Biol 71:315-345

$>$ Huse I, Ona E (1996) Tilt angle distribution and swimming speed of overwintering Norwegian spring spawning herring. ICES J Mar Sci 53:863-873

ICES (2007) Report of the working group on the assessment of demersal stocks in the North Sea and Skagerrak. ICES CM 2007/ACFM:18. International Council for the Exploration of the Sea, Copenhagen

Kaartvedt S, Røstad A, Klevjer TA (2009) Sprat Sprattus sprattus can exploit low oxygen waters for overwintering. Mar Ecol Prog Ser 390:237-249

Kawecki TJ, Ebert D (2004) Conceptual issues in local adaptation. Ecol Lett 7:1225-1241

Kvist T, Gislason H, Thyregod P (2001) Sources of variation in the age composition of sandeel landings. ICES J Mar Sci 58:842-851

Lima SL (1998) Nonlethal effects in the ecology of predatorprey interactions-What are the ecological effects of antipredator decision-making? Bioscience 48:25-34

Lima SL, Dill LM (1990) Behavioral decisions made under the risk of predation-a review and prospectus. Can J Zool 68:619-640

Macer CT (1966) Sandeels (Ammodytidae) in the southwestern North Sea: their biology and fishery. MAFF Fishery Invest London Ser II 24:1-55
MacLeod CD, Santos MBA, Reid RJ, Scott BE, Pierce GJ (2007) Linking sandeel consumption and the likelihood of starvation in harbour porpoises in the Scottish North Sea: Could climate change mean more starving porpoises? Biol Lett 3:185-188

Mangel M (1991) Adaptive walks on behavioral landscapes and the evolution of optimal behavior by natural selection. Evol Ecol 5:30-39

Mangel M, Stamps J (2001) Trade-offs between growth and mortality and the maintenance of individual variation in growth. Evol Ecol Res 3:583-593

Mittelbach GG (1981) Foraging efficiency and body sizea study of optimal diet and habitat use by bluegills. Ecology 62:1370-1386

Mylius SD, Diekmann O (1995) On evolutionary stable life histories, optimization and the need to be specific about density dependence. Oikos 74:218-224

> Pedersen J, Hislop JRG (2001) Seasonal variations in the energy density of fishes in the North Sea. J Fish Biol 59: 380-389

- Pedersen SA, Lewy P, Wright P (1999) Assessments of the lesser sandeel (Ammodytes marinus) in the North Sea based on revised stock divisions. Fish Res 41:221-241

Railsback SF, Lamberson RH, Harvey BC, Duffy WE (1999) Movement rules for individual-based models of stream fish. Ecol Model 123:73-89

Reeves SA (1994) Seasonal and annual variation in catchability of sandeels at Shetland. ICES CM D:19. International Council for the Exploration of the Sea, Copenhagen

> Schmitz OJ, Grabowski JH, Peckarsky BL, Preisser EL, Trussell GC, Vonesh JR (2008) From individuals to ecosystem function: Toward an integration of evolutionary and ecosystem ecology. Ecology 89:2436-2445

Schultz ET, Conover DO (1997) Latitudinal differences in somatic energy storage: Adaptive responses to seasonality in an estuarine fish (Atherinidae: Menidia menidia). Oecologia 109:516-529

Schultz ET, Conover DO (1999) The allometry of energy reserve depletion: test of a mechanism for size-dependent winter mortality. Oecologia 119:474-483

> Sharples J, Ross ON, Scott BE, Greenstreet SPR, Fraser H (2006) Inter-annual variability in the timing of stratification and the spring bloom in the north-western North Sea. Cont Shelf Res 26:733-751

> Sharples RJ, Arrizabalaga B, Hammond PS (2009) Seals, sandeels and salmon: diet of harbour seals in St. Andrews Bay and the Tay Estuary, southeast Scotland. Mar Ecol Prog Ser 390:265-276

Sherman K, Jones C, Sullivan L, Smith W, Berrien P, Ejsymont $L$ (1981) Congruent shifts in sand eel abundance in western and eastern North-Atlantic ecosystems. Nature 291:486-489

Stearns SC (1992) The evolution of life histories. Oxford University Press, New York, NY

$>$ Temming A, Gotz S, Mergardt N, Ehrich S (2004) Predation of whiting and haddock on sandeel: aggregative response, competition and diel periodicity. J Fish Biol 64:1351-1372

Van der Kooij J, Scott BE, Mackinson S (2008) The effects of environmental factors on daytime sandeel distribution and abundance on the Dogger Bank. J Sea Res 60:201-209

> Van Pelt TI, Piatt JF, Lance BK, Roby DD (1997) Proximate composition and energy density of some north pacific forage fishes. Comp Biochem Physiol A 118:1393-1398

- Varpe Ø, Fiksen Ø (2010) Seasonal plankton-fish interactions: light regime, prey phenology, and herring foraging. Ecology 91:311-318

Via S, Lande R (1985) Genotype-environment interaction 
and the evolution of phenotypic plasticity. Evolution 39: 505-522

Werner EE, Anholt BR (1993) Ecological consequences of the trade-off between growth and mortality rates mediated by foraging activity. Am Nat 142:242-272

Werner EE, Gilliam JF, Hall DJ, Mittelbach GG (1983) An experimental test of the effects of predation risk on habitat use in fish. Ecology 64:1540-1548

Winslade P (1971) Behavioural and embryological studies on lesser sandeel, Ammodytes marinus (Raitt). PhD thesis, University of East Anglia, Norwich

Winslade P (1974a) Behavioral studies on the lesser sandeel Ammodytes marinus (Raitt). III. Effect of temperature on activity and the environmental control of the annual cycle of activity. J Fish Biol 6:587-599

Editorial responsibility: Nicholas Tolimieri,

Seattle, Washington, USA
Winslade P (1974b) Behavioral studies on the lesser sandeel Ammodytes marinus (Raitt). I. Effect of food availability on activity and role of olfaction in food detection. J Fish Biol 6:565-576

- Winslade P (1974c) Behavioral studies on the lesser sandeel Ammodytes marinus (Raitt). II. Effect of light intensity on activity. J Fish Biol 6:577-586

Yamada H (2009) Reproductive potential and recruitment of sand lance Ammodytes personatus in Ise Bay, central Japan. Fish Sci 75:851-861

> Yamaguchi A, Ikeda T (2000) Vertical distribution, life cycle, and developmental characteristics of the mesopelagic calanoid copepod Gaidius variabilis (Aetideidae) in the Oyashio region, western North Pacific Ocean. Mar Biol 137:99-109

Submitted: January 18, 2010; Accepted: August 4, 2010 Proofs received from author(s): October 8, 2010 